\title{
Type B intramural hematomas and penetrating aortic ulcers: clinical comment on management and outlook
}

\author{
Eduardo Bossone ${ }^{1}$, Rosangela Cocchia ${ }^{1}$, Brigida Ranieri ${ }^{2}$, Kim Eagle $^{3}$ \\ ${ }^{1}$ Echo-Lab, Division of Cardiology, A. Cardarelli Hospital, Naples, Italy; ${ }^{2}$ Cardiovascular Imaging Unit, IRCCS SDN, Naples, Italy; ${ }^{3}$ University of \\ Michigan Frankel Cardiovascular Center, Ann Arbor, Michigan, USA \\ Correspondence to: Eduardo Bossone, MD, PhD, FCCP, FESC, FACC. Director, Cardiology Division, "Antonio Cardarelli” Hospital, Via A. \\ Cardarelli, 9, 80131 Naples, Italy. Email: ebossone@hotmail.com.
}

Submitted Mar 15, 2019. Accepted for publication May 09, 2019.

doi: $10.21037 /$ acs.2019.05.14

View this article at: http://dx.doi.org/10.21037/acs.2019.05.14

Intramural hematomas (IMH) and penetrating aortic ulcers (PAU) represent $10-25 \%$ and $2-7 \%$ of acute aortic syndromes (AAS), respectively $(1,2)$. These conditions are commonly located in the thoracic descending aorta (type B) and mainly affect the elderly (1,3-5). Despite substantial diagnostic and therapeutic advances, the in-hospital and long-term mortality remains high $(1,3)$. Therapeutic interventions are quite similar to those implemented for classic acute aortic dissection (AAD), mainly consisting of surgery for type A, medical therapy for uncomplicated type $B$ and endovascular treatment (TEVAR/EVAR) for complicated type B (1,3-4). In this regard, predictors of complications from IMH include persistent and recurrent pain despite aggressive medical treatment, difficulties in blood pressure control, ascending aortic involvement, maximum aortic diameter $\geq 50 \mathrm{~mm}$, progressive maximum aortic wall thickness $(>11 \mathrm{~mm})$, enlarging aortic diameter, recurrent pleural effusion, penetrating ulcer or ulcerlike projection secondary to localized dissections in the involved segment, and organ ischemia (brain, myocardium, bowels, kidneys, etc.) $(1,5)$. Moreover, in type B intramural haematoma, focal intimal disruption (FID) has been described in $>20 \%$ of cases with an unclear prognosis and management $(1,6)$. In PAU, refractory symptoms, rapidly growing lesions, associated periaortic haematoma or pleural effusions all call for an invasive strategy that should be also considered in the case of asymptomatic patients with ulcer diameter $>20 \mathrm{~mm}$ or neck $>10 \mathrm{~mm}(1,2,4)$.

However, a wide grey zone exists between complicated and uncomplicated cases. Ultimately, the management strategy should be tailored to each individual patient with the goal of intercepting early "warning signals" preceding clinical instability $(1,2)$. Interestingly, the detection of sustained elevated serologic markers (mainly D-dimer) may predict worse prognosis in otherwise apparently clinical stable patients $(7,8)$. However, randomized controlled trials comparing TEVAR $v s$. medical therapy will be needed to further delineate the most appropriate management of these conditions (9).

It should be highlighted that as for AAD, IMH and PAU represent a lifelong condition affecting the entire aorta $(1,2)$. Affected patients warrant close clinical and imaging surveillance (before discharge and at 1, 3, 6, and 12 months) and thereafter every year, depending on clinical conditions (1). Among imaging techniques, MRI (being radiation-free) remains the most suitable. If not available, CT represents a valid alternative. Applying the same imaging technique and side-by-side comparisons during follow-up visits allows for serial imaging to identify changes in shape or size that indicate instability $(1,10)$.

The main purpose of medical therapy is to achieve optimal blood pressure $(<120 / 80 \mathrm{mmHg})$ and heart rate $(<60 \mathrm{bpm})$ control and to reduce wall stress and pressuretime differential. In this regard, beta-blockers represent the first-line approach in combination with ACE inhibitors or $\mathrm{ARBs}$ (second line) and long-acting dihydropyridine calcium channel blockers (third line). Aggressive lipid management should target atherosclerosis or dyslipidemia, with a target LDL of $<70 \mathrm{mg} / \mathrm{dL}$. This is particularly true for PAU, which is often an extreme focal anatomopathological expression of systemic atherosclerosis affecting the entire aorta as well as coronary and peripheral arteries (1-3). 
It remains essential to allocate specific resources in order to design educational programs encouraging smoking cessation and control of other atherosclerotic risk factors. Not to be underestimated is the critical issue of adherence to medical treatment and counseling in the presence of genetic disease affecting the aorta (syndromic and non-syndromic) (2). While we've come a long way in both understanding and treating these unique aortic conditions, there is so much more that we must do in order to better prevent, diagnose, treat and follow patients afflicted by them.

\section{Acknowledgments}

None.

\section{Footnote}

Conflicts of Interest: The authors have no conflicts of interest to declare.

\section{References}

1. Erbel R, Aboyans V, Boileau C, et al. 2014 ESC Guidelines on the diagnosis and treatment of aortic diseases:

Document covering acute and chronic aortic diseases of the thoracic and abdominal aorta of the adult. The Task Force for the Diagnosis and Treatment of Aortic Diseases of the European Society of Cardiology (ESC). Eur Heart J 2014;35:2873-926.

2. Bossone E, LaBounty TM, Eagle KA. Acute aortic syndromes: diagnosis and management, an update. Eur

Cite this article as: Bossone E, Cocchia R, Ranieri B, Eagle K. Type B intramural hematomas and penetrating aortic ulcers: clinical comment on management and outlook. Ann Cardiothorac Surg 2019;8(4):490-491. doi: 10.21037/ acs.2019.05.14
Heart J 2018;39:739-49d.

3. Evangelista A, Isselbacher EM, Bossone E, et al. Insights From the International Registry of Acute Aortic Dissection: A 20-Year Experience of Collaborative Clinical Research. Circulation 2018;137:1846-60.

4. Jánosi RA, Gorla R, Tsagakis K, et al. Thoracic Endovascular Repair of Complicated Penetrating Aortic Ulcer: An 11-Year Single-Center Experience. J Endovasc Ther 2016;23:150-9.

5. von Kodolitsch Y, Csösz SK, Koschyk DH, et al. Intramural hematoma of the aorta: predictors of progression to dissection and rupture. Circulation 2003;107:1158-63.

6. Evangelista A, Mukherjee D, Mehta RH, et al. Acute intramural hematoma of the aorta: a mystery in evolution. Circulation 2005;111:1063-70.

7. Suzuki T, Bossone E, Sawaki D, et al. Biomarkers of aortic diseases. Am Heart J 2013;165:15-25.

8. Gorla R, Erbel R, Kuehl H, et al. Prognostic value of (18) F-fluorodeoxyglucose PET-CT imaging in acute aortic syndromes: comparison with serological biomarkers of inflammation. Int J Cardiovasc Imaging 2015;31:1677-85.

9. Nienaber CA, Kische S, Rousseau H, et al. INSTEAD$\mathrm{XL}$ trial. Endovascular repair of type B aortic dissection: long-term results of the randomized investigation of stent grafts in aortic dissection trial. Circ Cardiovasc Interv 2013;6:407-16.

10. Baliga RR, Nienaber CA, Bossone E, et al. The role of imaging in aortic dissection and related syndromes. JACC Cardiovasc Imaging 2014;7:406-24. 